\title{
Influence of the Testing Gage Length on the Strength, Young's Modulus and Weibull Modulus of Carbon Fibres and Glass Fibres
}

\author{
Luiz Claudio Pardini ${ }^{\text {a*, Luis Guilherme Borzani Manhani }}{ }^{\mathrm{b}}$ \\ ${ }^{a}$ Centro Técnico Aeroespacial, Instituto de Aeronáutica e Espaço, \\ Divisão de Materiais - AMR, 12228-904 São José dos Campos - SP, Brazil \\ ${ }^{\mathrm{b}}$ Centro Técnico Aeroespacial, Instituto Tecnológico de Aeronáutica, \\ Departamento de Física, 12228-900 São José dos Campos - SP, Brazil
}

Received: January 21, 2002; Revised: October 04, 2002

\begin{abstract}
Carbon fibres and glass fibres are reinforcements for advanced composites and the fiber strength is the most influential factor on the strength of the composites. They are essentially brittle and fail with very little reduction in cross section. Composites made with these fibres are characterized by a high strength/density ratio and their properties are intrisically related to their microstructure, i.e., amount and orientation of the fibres, surface treatment, among other factors. Processing parameters have an important role in the fibre mechanical behaviour (strength and modulus). Cracks, voids and impurities in the case of glass fibres and fibrillar misalignments in the case of carbon fibres are created during processing. Such inhomogeneities give rise to an appreciable scatter in properties. The most used statistical tool that deals with this characteristic variability in properties is the Weibull distribution. The present work investigates the influence of the testing gage length on the strength, Young's modulus and Weibull modulus of carbon fibres and glass fibres. The Young's modulus is calculated by two methods: (i) ASTM D 3379M, and (ii) interaction between testing equipment/specimen The first method resulted in a Young modulus of $183 \mathrm{GPa}$ for carbon fibre, and $76 \mathrm{GPa}$ for glass fibre. The second method gave a Young modulus of $250 \mathrm{GPa}$ for carbon fibre and $50 \mathrm{GPa}$ for glass fibre. These differences revelead differences on how the interaction specimen/testing machine can interfere in the Young modulus calculations. Weibull modulus can be a tool to evaluate the fibre's homogeneity in terms of properties and it is a good quality control parameter during processing. In the range of specimen gage length tested the Weibull modulus for carbon fibre is $\sim 3.30$ and for glass fibres is $\sim 5.65$, which indicates that for the batch of fibres tested, the glass fibre is more uniform in properties.
\end{abstract}

Keywords: carbon fibres, glass fibres, Young modulus, Weibull modulus.

\section{Introduction}

A considerable progress over the past three decades has been made in the reinforcement technology, but as many other things, they were not created equally. Many factors contribute to the variability in properties, and the key factors that influence mechanical properties are raw material and processing conditions. Carbon fibres, for instance, are mainly manufactured by spinning termoplastic fibres, predominantly polyacrilonitrile and pitch, which under controlled drawing and pyrolysis are converted to stiff oriented carbon. As a consequence their mechanical properties vary according to the characteristics of the precursor fibre and the processing itself. During precursor manufacturing and further heat treatment many defects are created, such as, fibrilar misalignments and many ultramicropores, which result in scatter in carbon fibre strength. Glass fibres in turn are obtained by melting and melt spinning a mixture of metal oxides. Thus, it is necessary to implement a statistical process control or qualification programs in order to reduce the variability of fiber key characteristics. Therefore, the properties of structural composites are a function of both fibre

*e-mail: 1pardini@directnet.com.br 
distribution strength at short gauge lengths and fibre elastic modulus. On the other hand, composite properties are highly influenced by fibre/matrix bonding.

After processing, statistic control or qualification programs applied to reinforcing fibres are based on evaluation of mechanical properties. Tensile strength is a straightforward measurement on fibres. Although filaments can be as thin as $\sim 7.5 \mu \mathrm{m}$ in diameter they can be easily fitted in paper tab and tensile tests can be performed in a simple way. On the other hand, their inherent brittleness cause difficulties to measure deformation by standard strain-sensing devices, such as strain-gages, extensometers, etc, or by other more sophisticated and expensive techniques such as optical methods. So, the first aim of this work is to use two methodologies to calculate the modulus. The first one is based on the system compliance, as stated in the ASTM D $3379 \mathrm{M}^{1}$, and the second one takes into account the rigidity of the equipment where fibres are tested. In the latter method the results of the tensile test reflect the interaction between the testing equipment and specimen under test ${ }^{2}$. Both methods used the same set of data for calculations. The literature reports for high strength carbon fibre a tensile strength of $3.0 \mathrm{GPa}$ and a Young modulus of $230.0 \mathrm{GPa}^{3}$. For glass fibres an average tensile strength of $2.2 \mathrm{GPa}$ and Young modulus in the range of $60.0 \mathrm{GPa}$ to 90.0 GPa are reported.

Unlike many other physical parameters such as elastic modulus, density, etc, filament strength is a statistical parameter which can not be fully described by a single value. The most used statistical tool to describe the variability in strength for materials is the Weibull distribution. The Weibull modulus is not a material constant, but gives a good indication of how homogeneous the material is.

\section{Materials and Experimental}

In the present work the carbon fibre studied was a PANbased high strength 400 dtex type, manufactured by Hexcel Carbon Fibres, under the trade name of AS4-GP. E-glass type fibres were provided by Owens Corning Ltda, 750 dtex. Both fibres were tested according to the ASTM D 3379M Standard. The fibres were cut in dissimilar positions from the fibre tow assuring a random selection of single filaments. Gage lengths of $25 \mathrm{~mm}, 50 \mathrm{~mm}, 75 \mathrm{~mm}$ and $100 \mathrm{~mm}$ were prepared by moulting in a paper support tab, as shown in Fig. 1. The testing speed was $2.5 \mathrm{~mm} / \mathrm{min}$, graphic paper speed was $200 \mathrm{~mm} / \mathrm{min}$. The testing machine used during the work was an Instron 1131, and a load cell of $50 \mathrm{gf}$ was used. For carbon fibres the full scale testing was set at $20 \mathrm{gf}$ and for glass fibre the full scale testing was set at $50 \mathrm{gf}$. At least twenty-five specimens were tested from each kind of fibre.

The tensile test gives us a load as a function of extension

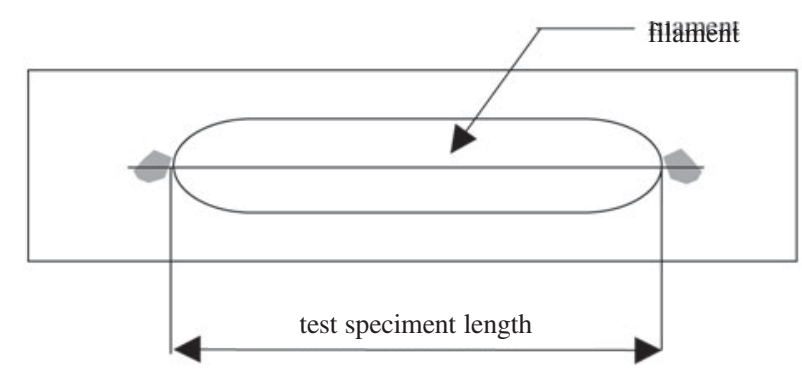

Figure 1. Support tab for testing fibre filaments according to ASTM D $3379 \mathrm{M}^{1}$.

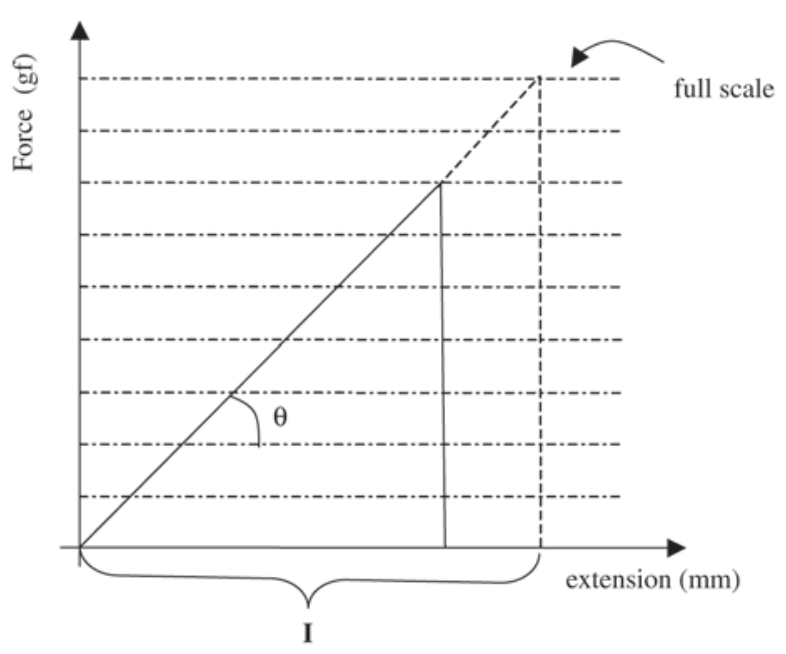

Figure 2. Graphic representation of a tensile test of fibre single filament.

curve up to failure. Tensile strength was calculated as follows:

$$
\sigma=\mathrm{F} / \mathrm{A}
$$

where $\mathrm{F}=$ tensile force to failure $(\mathrm{N}), \mathrm{A}=$ average cross section filament area $\left(\mathrm{m}^{2}\right)$.

The carbon fibre modulus was calculated following two procedures. The first is described in ASTM D 3379M Standard. The procedure suggests that indicated compliance is first calculated as follows:

$$
\mathrm{Ca}=(\mathrm{I} / \mathrm{P}) \times(\mathrm{H} / \mathrm{S})
$$

where $\mathrm{I}=$ total extension for the straight line section of load/time curve extrapolated across full chart scale $(\mathrm{mm})$, $\mathrm{H}=$ crosshead speed $(\mathrm{mm} / \mathrm{s}), \mathrm{P}=$ full scale force $(\mathrm{N})$, 
$\mathrm{S}=$ chart speed $(\mathrm{mm} / \mathrm{s})$. The true compliance is then calculated as:

$$
\mathrm{C}=\mathrm{Ca}-\mathrm{Cs}
$$

where $\mathrm{C}=$ true compliance $(\mathrm{mm} / \mathrm{N}), \mathrm{Cs}=$ system compliance $(\mathrm{mm} / \mathrm{N})$.

The Young's Modulus is calculated as a corrected value by the equation :

$$
\mathrm{E}=\mathrm{L} /(\mathrm{C} \times \mathrm{A})
$$

where $\mathrm{E}=$ Young modulus $(\mathrm{GPa}), \mathrm{L}=$ specimen gage length $(\mathrm{mm}), \mathrm{C}=$ True compliance $(\mathrm{mm} / \mathrm{N})$, and $\mathrm{A}=$ average filament area $\left(\mathrm{mm}^{2}\right)$.

The second method to correct the Young modulus value followed a procedure which takes into account the interaction between equipment/specimen during testing, as described by Guimarães ${ }^{2}$. According to this method the equipment and the specimen are considered as two springs in series, as shown in Fig. 3, one representing the testing machine having a rigidity $\left(\mathrm{K}_{\mathrm{m}}\right)$, and the other one representing the specimen having a rigidity proporcional to the Young's modulus, as follows ${ }^{2}$ :

$$
\frac{1}{K_{S}}=\frac{1}{K_{m}}+\left(\frac{1}{E}\right) \cdot \frac{L}{A}
$$

where $\mathrm{K}_{\mathrm{s}}$ is the rigidity of the system, $\mathrm{L}$ is the specimen length, $\mathrm{E}=$ Young's modulus, $\mathrm{A}=$ cross section area of the specimen.

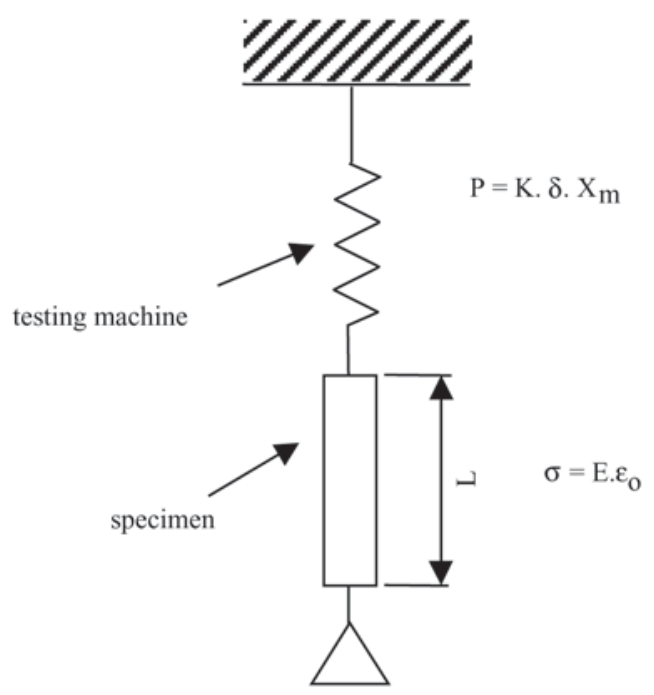

Figure 3. Representation of the testing system equipment/specimen in the elastic regime. $\mathrm{K}=$ testing machine spring constant, $\delta . \mathrm{X}_{\mathrm{m}}=$ displacement due to testing machine elasticity.
At the onset of the test, the specimen is in the elastic regime and the slope of the load/extension curve can be used to calculate $\mathrm{K}_{\mathrm{s}}$, as follows:

$$
\mathrm{K}_{\mathrm{s}}=\operatorname{tg}\left(\theta_{\mathrm{o}}\right)
$$

The angle $\theta_{\mathrm{o}}$ is measured, as indicated in Fig. 2, and Young's modulus can be calculated by the Eq. 7:

$$
K_{m}=\left[\left(\operatorname{tg} \theta_{\mathrm{o}}\right)^{-1}-\left(\frac{L_{o} / A_{o}}{E}\right)\right]^{-1} \Rightarrow\left(\operatorname{tg} \theta_{\mathrm{o}}\right)^{-1}=\frac{1}{K_{m}}+\frac{1}{E} \cdot\left(\frac{L_{o}}{A_{o}}\right)
$$

where $\mathrm{L}_{\mathrm{o}}$ and $\mathrm{A}_{\mathrm{o}}$ are the initial gage length and cross section area of the filament specimen.

If $\theta_{\mathrm{o}}$ is known, and " $\operatorname{tg} \theta_{\mathrm{o}}$ " is plotted as a function of $\mathrm{L}_{\mathrm{o}} / \mathrm{A}_{\mathrm{o}}$, values for $\mathrm{K}_{\mathrm{m}}$ and $\mathrm{E}$ can be obtained. Correction of the elastic modulus is necessary because the testing equipment can exhibit a dependency where the equipment response during testing is dependent on the sample gage length. This dependency is manifested as an elastic deformation contribution from the testing equipment.

The Weibull modulus from each set of fibre tested was determined at different gage lengths. This was accomplished by plotting Eq. $8^{4}$ :

$$
\ln \ln \left(\frac{1}{1-P}\right)=m \cdot \ln \sigma-m \cdot \ln \sigma_{o}
$$

where $\mathrm{P}$ is the probability of failure, $\mathrm{m}$ is the Weibull shape parameter, $\sigma$ is the tensile strength and $\sigma_{\mathrm{o}}$ is the scale parameter.

The Weibull modulus is obtained by plotting $\ln [\ln (1 /(1-\mathrm{P}))]$ as function of $\ln \sigma$. The probability from mean position corresponding to the $i$-th observation is given by $\mathrm{P}=\mathrm{i} / \mathrm{N}+\mathrm{i}$, where $\mathrm{N}$ is the number of samples. The Weibull parameter $(\mathrm{m})$ is obtained by linear regression.

\section{Results and Discussions}

Initially, Hookean behaviour was assumed for glass and carbon fibres in the calculation of Young's modulus. Table 1 show results for tensile tests for carbon fibre. It shows a trend where the higher gage length of the fibre filament is the lower the tensile strength obtained is. This trend has been also reported by other researchers, and it is related to the increase in flaw population when higher gage length is used for testing 5 . Table 2 shows the results obtained for tensile tests for glass fibres and a similar behaviour was found for these fibres when compared to carbon fibres.

All fibres failed in a brittle manner by exhibiting a sharp drop in strength after ultimate failure stress. Mean values for tensile strength for carbon fibres and for glass fibres were close to each other. The tensile strength reported in 
Table 1. Properties of the carbon fibre at various specimen gage length.

\begin{tabular}{ccccc}
\hline $\begin{array}{c}\text { Specimen gage } \\
\text { length }(\mathrm{mm})\end{array}$ & $\begin{array}{c}\text { Tensile strength } \\
(\mathrm{GPa})\end{array}$ & $\begin{array}{c}\text { Extension at } \\
\text { break }(\mathrm{mm})\end{array}$ & $\begin{array}{c}\text { Calculated strain } \\
(\%)^{*}\end{array}$ & $\begin{array}{c}\text { Young's modulus } \\
(\mathrm{GPa}) *\end{array}$ \\
\hline 25 & $2.90 \pm 0.97$ & 0.325 & 1.318 & 220.0 \\
50 & $2.70 \pm 0.72$ & 0.5631 & 1.126 & 240.0 \\
75 & $2.66 \pm 0.87$ & 0.8351 & 1.113 & 240.0 \\
100 & $2.54 \pm 0.80$ & 1.0882 & 1.088 & 233.0 \\
Average & $2.70 \pm 0.15$ & - & $1.1612 \pm 0.10$ & $233.0 \pm 9.4$ \\
\hline
\end{tabular}

* assuming ideal Hookean behaviour.

Table 2. Properties of glass fibres at various specimen gage length.

\begin{tabular}{ccccc}
\hline $\begin{array}{c}\text { Specimen gage } \\
\text { length }(\mathrm{mm})\end{array}$ & $\begin{array}{c}\text { Tensile strength } \\
(\mathrm{GPa})\end{array}$ & $\begin{array}{c}\text { Extension at } \\
\text { break }(\mathrm{mm})\end{array}$ & $\begin{array}{c}\text { Calculated strain } \\
(\%)^{*}\end{array}$ & $\begin{array}{c}\text { Young's modulus } \\
(\mathrm{GPa})^{*}\end{array}$ \\
\hline 25 & $2.58 \pm 0.40$ & 0.83 & 3.30 & 78.00 \\
50 & $2.27 \pm 0.50$ & 1.19 & 2.40 & 95.60 \\
75 & $2.43 \pm 0.48$ & 1.60 & 2.50 & 97.00 \\
100 & $2.18 \pm 0.40$ & 2.38 & 2.40 & 91.60 \\
Average & $2.38 \pm 0.19$ & - & $2.65 \pm 0.43$ & $90.50 \pm 8.70$ \\
\hline
\end{tabular}

* assuming ideal Hookean behaviour.

the literature for both glass fibres and carbon fibres are close to the value found in this work, $2.70 \mathrm{GPa}$ and $2.38 \mathrm{GPa}$ respectively.

Figure 4 shows a plot of tensile strength as a function of gage length for glass fibres. Glass fibre tensile strength tends, although not regularly, to a decrease in strength with an increase in the gage length tested. On the other hand, Fig. 5 shows that an increase in the carbon fibre gage length leads to a decrease in the tensile strength. The decrease in tensile strength with increasing gage length tested is mainly associated with an increase in flaw population ${ }^{5}$.

As it could be expected, a large difference was found in Young's modulus values for glass fibres (90 GPa) and for carbon fibres (233 GPa). This is due to their atomic structure $^{6}$. Essentially, PAN-based carbon fibres are nongraphitizing with a turbostratic (irregular) organisation of the graphitic layer planes, and the most realistic model of the structure consists of a complex fibrillar structure threedimensionally interlinked forming crystallites which enclose sharp-edged voids ${ }^{7}$. In E-glass type fibres the presence of elements such as $\mathrm{Ca}, \mathrm{Na}$ and $\mathrm{K}$ tends to break up the regular network of the three-dimensional covalent bonded tetrahedral formed in the presence of silicon, at the centre, and oxygen at the corners. This can cause regions of inhomogeneities in fibre structure at different levels and hence causes variation in strength ${ }^{8}$.

Results from Table 1 and Table 2 indicate that for the onset of fracture, the energy necessary to break chemical

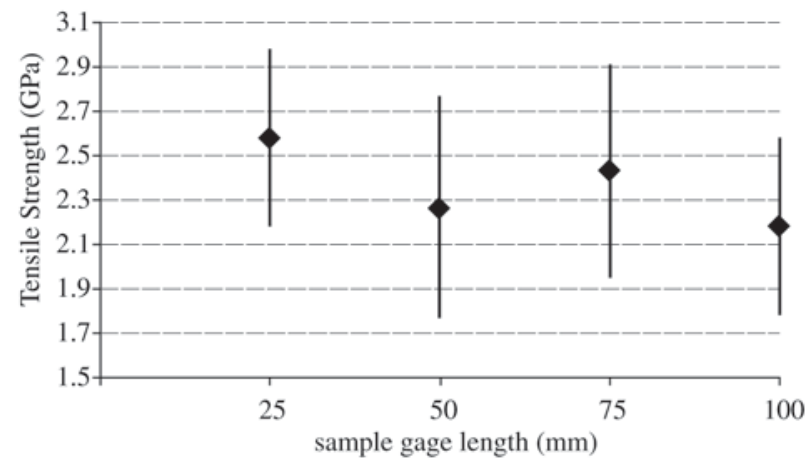

Figure 4. Tensile strength as a function of sample gage length for glass fibres.

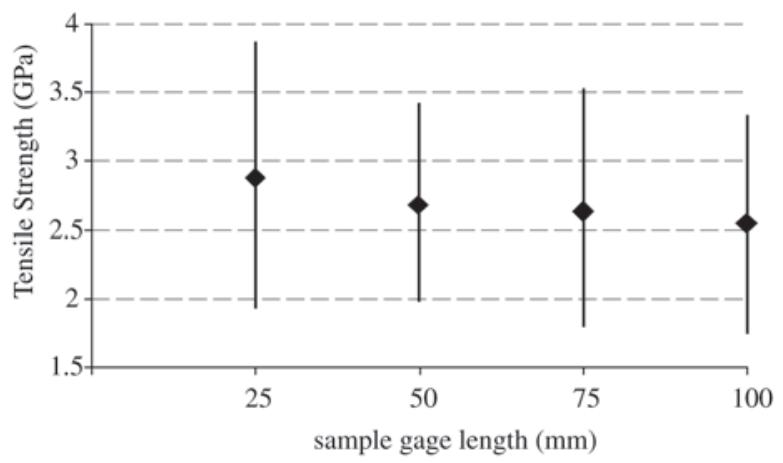

Figure 5. Tensile strength as a function of sample gage length for carbon fibres. 
bonds in glass fibres is twice as high as the energy necessary for carbon fibres. Table 1 and Table 2 also show results for Young's modulus by assuming Hookean behaviour for both fibres. The results showed that glass fibre Young's modulus is higher than the ones found in the literature. For carbon fibres, the results for Young's modulus agreed well with those from the literature. As stated earlier in this work, carbon and glass filaments are very thin and, as a consequence, it is not possible to attach strain-gages to these fibres. As a result, Young's modulus obtained can be misleading by assuming the ideal Hookean behaviour. So, in the next sections it is present two methods for Young's modulus calculations, as following :

- Calculation of Young's modulus by ASTM 3329M method, and

- Calculation of Young's modulus by the rigidity method (interaction testing equipment/specimen)

\section{Calculation of Young's Modulus by ASTM D 3329M Method}

By using Eq. 4 the corrected Young's modulus can be calculated. The true compliance $(\mathrm{C})$ is obtained by subtract-

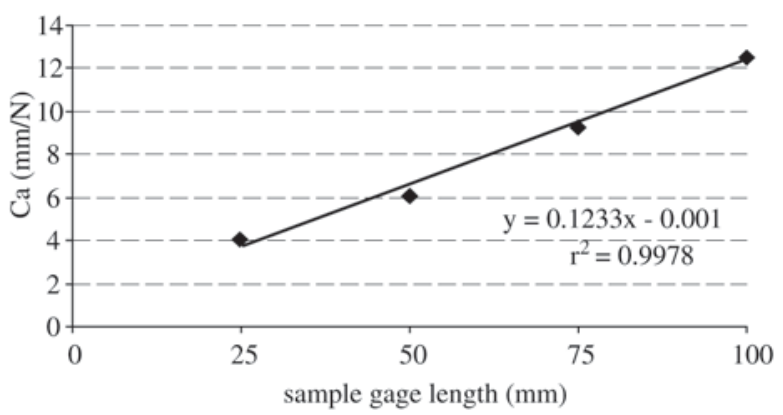

Figure 6. Graphical plot for the system (testing equipment) compliance for carbon fibres.

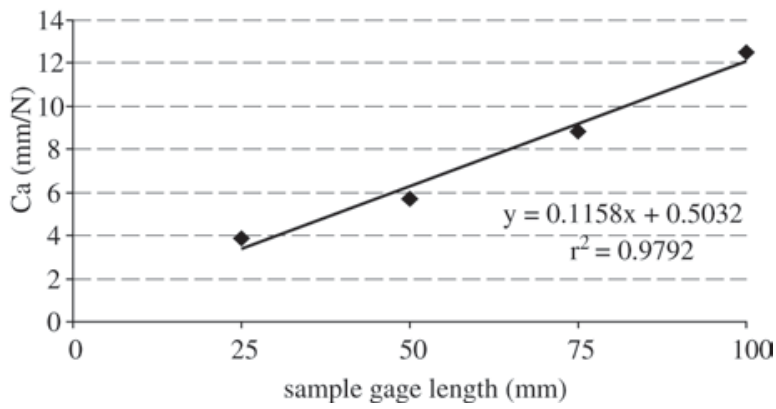

Figure 7. Graphical plot for the system (testing equipment) compliance for glass fibres. ing the system compliance (Cs), taking it at zero gage length in Fig. 6 for carbon fibres, and in Fig. 7 for glass fibres, from the indicated compliance $(\mathrm{Ca})$ for each gage length, using Eq. 2. The Fig. 8 shows plots for Young's modulus assuming ideal Hookean behaviour and the corrected Young's modulus according to ASTM D 3329M for carbon fibres and Fig. 9 shows equivalent plots for glass fibres.

According to ASTM D 3329M testing method, the corrected Young's modulus found for carbon fibres was $\sim 183.0 \pm 6.6 \mathrm{GPa}$, and $75.7 \pm 8.4 \mathrm{GPa}$ for glass fibres, Table 3 and Table 4, respectively. For high strength carbon fibre a Young's modulus of $\sim 220 \mathrm{GPa}$ is reported in the literature, the correction gives an underestimated value, although no information is given about testing conditions ${ }^{3}$. This result also indicates that correction by ASTM D 3329M gives a more conservative result. For glass fibres, however,

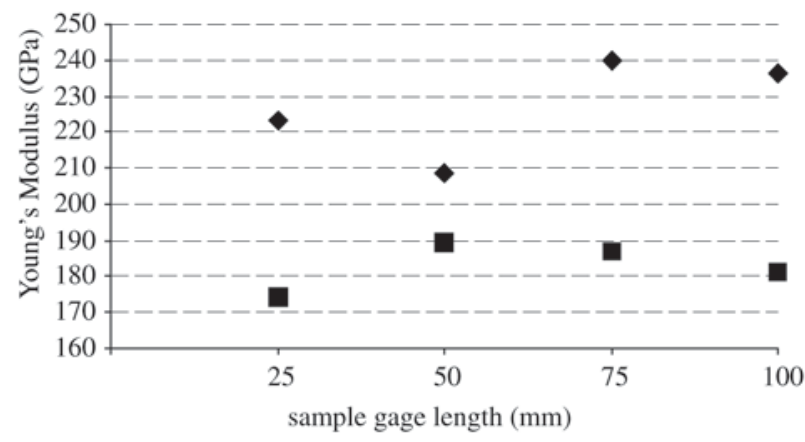

Figure 8. Young's modulus for carbon fibres. (u) assuming ideal Hookean behaviour, (g) corrected Young's modulus according to ASTM D 3329M.

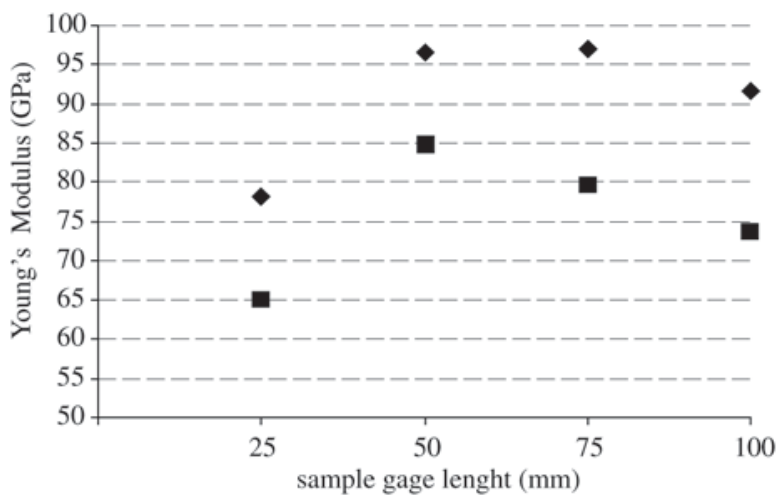

Figure 9. Young's modulus for glass fibres. (u) assuming ideal Hookean behaviour, $(\mathrm{g})$ corrected Young's modulus according to ASTM D 3329M. 
the corrected result agreed well with the value given by literature, where it is reported a Young's modulus of 70 GPa. As a result, by assuming ideal Hookean behaviour for both carbon and glass fibres, the results for Young's modulus are overestimated at any gage length tested.

Calculation of Young's Modulus by the Rigidity Method (Interaction Testing Equipment/Specimen)

This approach for modulus calculation needs initiallly the value of the angle $\theta_{0}$ from the load as a function of extension curve for each gage length of fibre tested, as exemplified in Fig. 2, and also the gage length/filament cross section $\left(\mathrm{L}_{\mathrm{o}} / \mathrm{A}_{\mathrm{o}}\right.$ ) ratio. Table 5 shows results for these parameters for both carbon and glass fibres. The graphical plot from the results showed in Table 5 are in Fig. 10 for carbon fibres $\left(A_{0}=4.78 .10^{-11} \mathrm{~m}^{2}\right)$ and Fig. 11 for glass fibres $\left(\mathrm{A}_{\mathrm{o}}=1.13 \cdot 10^{-10} \mathrm{~m}^{2}\right)$.

According to this method (rigidy method), the corrected

Table 3. Calculations for the corrected Young's modulus for carbon fibres, according to ASTM D 3329M.

\begin{tabular}{cccc}
\hline $\begin{array}{c}\text { Specimen gage } \\
\text { length }\left(\mathrm{L}_{\mathrm{o}}\right)(\mathrm{mm})\end{array}$ & $\begin{array}{c}\mathrm{Ca} \\
(\mathrm{mm} / \mathrm{N})\end{array}$ & $\begin{array}{c}\mathrm{Ci} \\
(\mathrm{mm} / \mathrm{N})\end{array}$ & $\begin{array}{c}\text { Ecorreted } \\
(\mathrm{GPa})\end{array}$ \\
\hline 25 & 3.2500 & 3.2489 & 174.2 \\
50 & 5.9795 & 5.9785 & 189.3 \\
75 & 9.1020 & 9.1010 & 186.5 \\
100 & 12.4816 & 12.4806 & 181.4 \\
& & Average $\Rightarrow$ & $182.9 \pm 6.6$ \\
\hline
\end{tabular}

Table 4. Calculations for the corrected Young's modulus for glass fibres, according to ASTM D 3329M.

\begin{tabular}{cccc}
\hline $\begin{array}{c}\text { Specimen gage } \\
\text { length }\left(\mathrm{L}_{\mathrm{o}}\right)(\mathrm{mm})\end{array}$ & $\begin{array}{c}\mathrm{Ca} \\
(\mathrm{mm} / \mathrm{N})\end{array}$ & $\begin{array}{c}\mathrm{Ci} \\
(\mathrm{mm} / \mathrm{N})\end{array}$ & $\begin{array}{c}\text { Ecorreted } \\
(\mathrm{GPa})\end{array}$ \\
\hline 25 & 3.9000 & 3.3969 & 65.1 \\
50 & 5.7209 & 5.2178 & 84.7 \\
75 & 8.8367 & 8.3336 & 79.6 \\
100 & 12.5145 & 12.0115 & 73.6 \\
& & Average $\Rightarrow 75.7 \pm 8.5$ \\
\hline
\end{tabular}

Young's modulus is given by the inverse of the angular coefficient. The Fig. 8 showing carbon fibre behaviour indicates that angular coefficient is equal to $4.10^{-7}$. Thus, the value of the corrected Young's modulus for the carbon fibre, obtained by rigidity method, is equal to $250 \mathrm{GPa}$. For glass fibre the angular coefficient taken from the plot of Fig. 9 is $2.10^{-6}$ results in a corrected Young's modulus equal to $50 \mathrm{GPa}$, which is below the lower bound for glass fibre Young's modulus found in literature. The rigidity method approach for Young's modulus calculation for carbon fiber

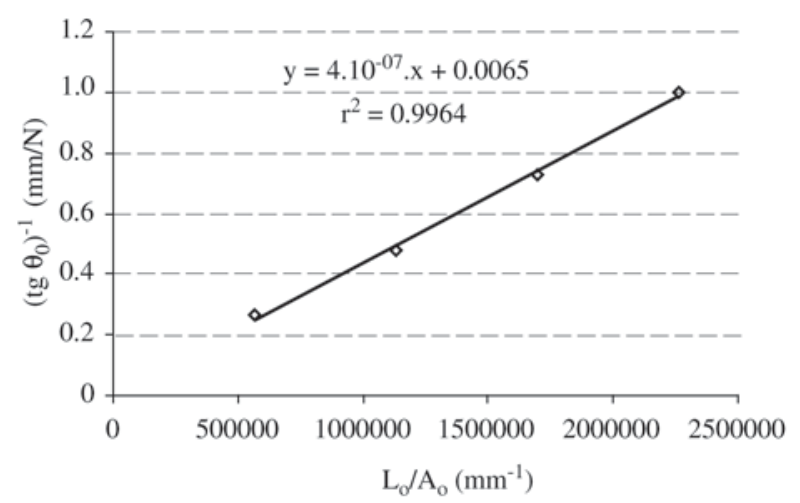

Figure 10. Graphical plot of Eq. 7 taken from experimental data from Table 5, for carbon fibres.

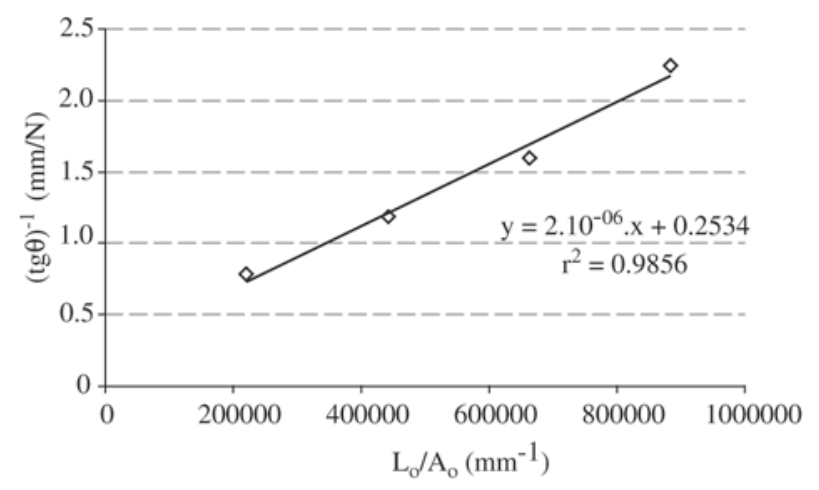

Figure 11. Graphical plot of equation 7 taken from experimental data from Table 5, for glass fibres.

Table 5. Results for $\left(\operatorname{tg} \theta_{o}\right)^{-1}$ and gage length/cross section area $\left(\mathrm{L}_{\mathrm{o}} / \mathrm{A}_{\mathrm{o}}\right)$ for each gage length tested, for carbon fibres and glass fibres.

\begin{tabular}{ccccc}
\hline & \multicolumn{2}{c}{ Carbon Fibre } & \multicolumn{2}{c}{ Glass Fibre } \\
Specimen Gage length $\left(\mathrm{L}_{\mathrm{o}}\right)(\mathrm{mm})$ & $\left(\operatorname{tg} \theta_{\mathrm{o}}\right)^{-1}$ & $\mathrm{~L}_{\mathrm{o}} / \mathrm{A}_{\mathrm{o}}\left(\mathrm{mm}^{-1}\right)$ & $\left(\operatorname{tg} \theta_{\mathrm{o}}\right)^{-1}$ & $\mathrm{~L}_{\mathrm{o}} / \mathrm{A}_{\mathrm{o}}\left(\mathrm{mm}^{-1}\right)$ \\
\hline 25 & 0.2680 & 565995 & 0.7812 & 221000 \\
50 & 0.4770 & 1131990 & 1.1904 & 442000 \\
75 & 0.7260 & 1697985 & 1.6000 & 663000 \\
100 & 1.0000 & 2263980 & 2.2461 & 884000 \\
\hline
\end{tabular}


agreed well with the value for Young's modulus found assuming a linear elastic behaviour during tensile tests $(\sim 233 \mathrm{GPa})$, and also agreed with the value given in the literature ${ }^{8}$.

The value of testing machine rigidity $\left(\mathrm{K}_{\mathrm{m}}\right)$ was calculated from Eq. (5). The value of $\mathrm{K}_{\mathrm{m}}$ depends on geometrical parameters of the specimen, Young's modulus and on angle $(\theta)$ of the load as function of displacement for the specimen. For carbon fibre the Young's modulus is much higher than for glass fibre and the angle $(\theta)$ of the load/displacement curve is steeper giving rise to a testing machine rigidity of $3.8 \mathrm{kN} / \mathrm{m}$. For glass fibres the Young's is lower than for carbon fibres and the angle $(\theta)$ of the load/displacement curve is also lower than that for carbon fibres giving rise to a higher testing machine rigidity $\left(\mathrm{K}_{\mathrm{m}}=13 \mathrm{kN} / \mathrm{m}\right)$. Thus, the INSTRON testing machine used in this work is almost three times stiffer for testing glass fibres than for testing carbon fibres.

\section{Weibull Modulus}

The tensile strength for both carbon fibre and glass fibre obtained in the present work were evaluated under constant volume, i.e., a set of samples had a constant gage length. The Weibull modulus for both carbon and glass fibres were calculated for each gage length tested according to Eq. 8 . The plots for carbon fibres at each gage length tested is shown in Fig. 12. The equation of the line draw through the points has the form " $y=a x+b$ ", where "a" represents the Weibull modulus , $^{4}$.

The Weibull parameter " $m$ " can be regarded as a flaw frequency distribution factor ${ }^{4}$. High values of " $m$ " indicates that flaws are evenly distributed throughout the material, whatever they are plentiful or not, and hence strength is nearly independent of the length. Low values of " $m$ " indicated that flaws are fewer and less evenly distributed, causing greater scatter in strength. All graphical plots of Weibull distribution for carbon fibres, obtained in the present work, showed that " $\mathrm{m}$ " falls in a narrow range $(\mathrm{m}=3.0-3.6)$, indicating that the latter assumption, fewer flaws less evenly distributed, is the case for carbon fibre. Flaws in carbon fibres are mainly represented by pores. The carbon fibre of the type used in this work is characterized by a mean pore diameter of about $5.5 \mathrm{~nm}$, and a broad ultramicropore distribution in the range of $2 \mathrm{~nm}$ to $40 \mathrm{~nm}$, and a pore volume of $\sim 0.2 \%{ }^{10}$. These figures indicate that strength statitics of carbon fibre is mainly controlled by small flaw population.

The Weibull theory also states that for a material with homogeneous quality having a near unimodal distribution of flaw size the value of " $m$ " should be the same at all sample length, and the mean value of strength at the different lengths should increase with decrease in length. The carbon fibre used in this work followed this trend, which indicates that it has an unimodal distribution of flaw size. De- spite the high scatter in the tensile strength values for carbon fibre $(\sim 30 \%)$, commonly found for this kind of material, the narrow range of " $m$ " parameter indicates that it has an homogeneous quality.

Tagawa ${ }^{11}$ investigated statistical distributions of the tensile strength in carbon fibres for 10 years period using exPAN carbon fibres and mesophase pitch carbon fibre. In his work a Weibull parameter of 4 was found, irrespective of the carbon fibre precursor and strength level. Tensile strength in the carbon fibres almost follows a single modal Weibull distribution, suggesting a single fracture mechanism. The fracture mechanism of carbon fibres is mainly due to misorientation of the graphite crystal layers around some inclusions and voids, which is assumed as a defect controlling mechanism.

Glass fibre shows a different picture from the carbon fibre behaviour, as shown in Fig. 13. The Weibull modulus varies at each gage length tested indicanting that mechanical properties of glass fibre is not homogeneous from bath to bath. It must be pointed out that surface defects are the cause of premature failure in fibres and these defects can also appear during fibre handling. Weibull modulus for glass fibre has a high value in relation to the Weibull modulus for carbon fibre. This indicates that the scatter in mechanical properties for the glass fibre is lower than that for carbon fibre, despite of the fact that glass fibre Weibull modulus exhibits a near constant value.

The average fracture stress is not a constant but depends on the specimen gage length. This change follows the Eq. $9^{12}$ :

$$
\frac{\sigma_{1}}{\sigma_{2}}=\left(\frac{\mathrm{L}_{2}}{\mathrm{~L}_{1}}\right)^{1 / m}
$$

Thus, just one Weibull modulus could be calculated from the set of fibres tested. Considering the average value of carbon fibre Weibull modulus (3.28) and the specimen gage length of $\mathrm{L}_{1}=25 \mathrm{~mm}$ and average values for tensile strength $\left(\sigma_{1}=2.90 \mathrm{GPa}\right)$, the resulting $\sigma_{2}$ tested at $\mathrm{L}_{2}=100 \mathrm{~mm}$ gage length would be $1.90 \mathrm{GPa}$, which is the lowest value for carbon fibre tensile strength.

Considering the average value of glass fibre Weibull modulus (5.76) and the specimen gage length of $\mathrm{L}_{1}=25 \mathrm{~mm}$ and average values for tensile strength $\left(\sigma_{1}=2.58 \mathrm{GPa}\right)$, the resulting $\sigma_{2}$ tested at $L_{2}=100 \mathrm{~mm}$ gage length would be $2.03 \mathrm{GPa}$, which is in the lower bound for glass fibre tensile strength.

\section{Conclusion}

Tensile strength, Young's modulus and Weibull modulus were evaluated for two types of reinforcements used 

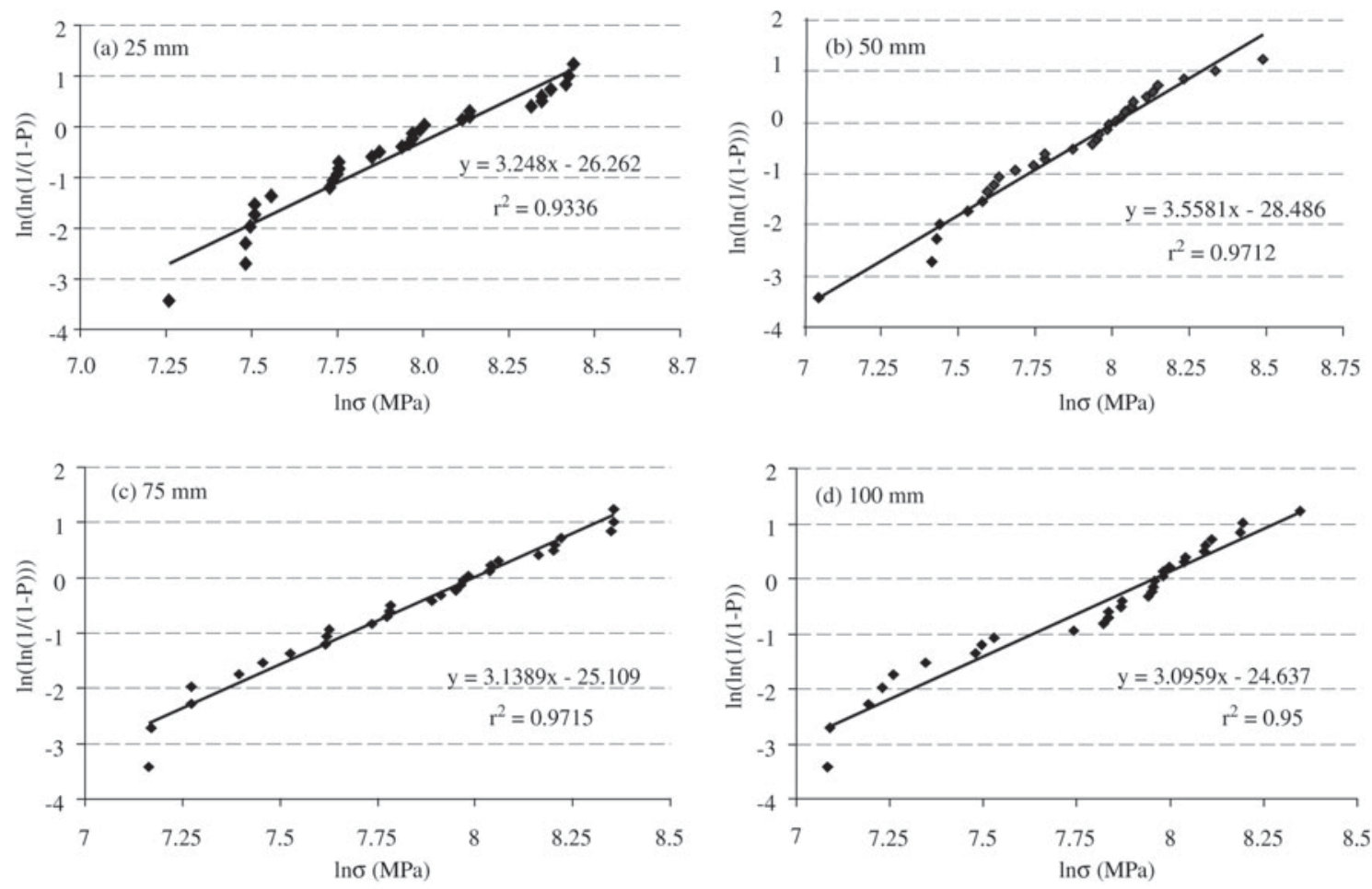

Figure 12. Weibull plots for tensile strength of carbon fibres of length $25 \mathrm{~mm}, 50 \mathrm{~mm}, 75 \mathrm{~mm}$ and $100 \mathrm{~mm}$.
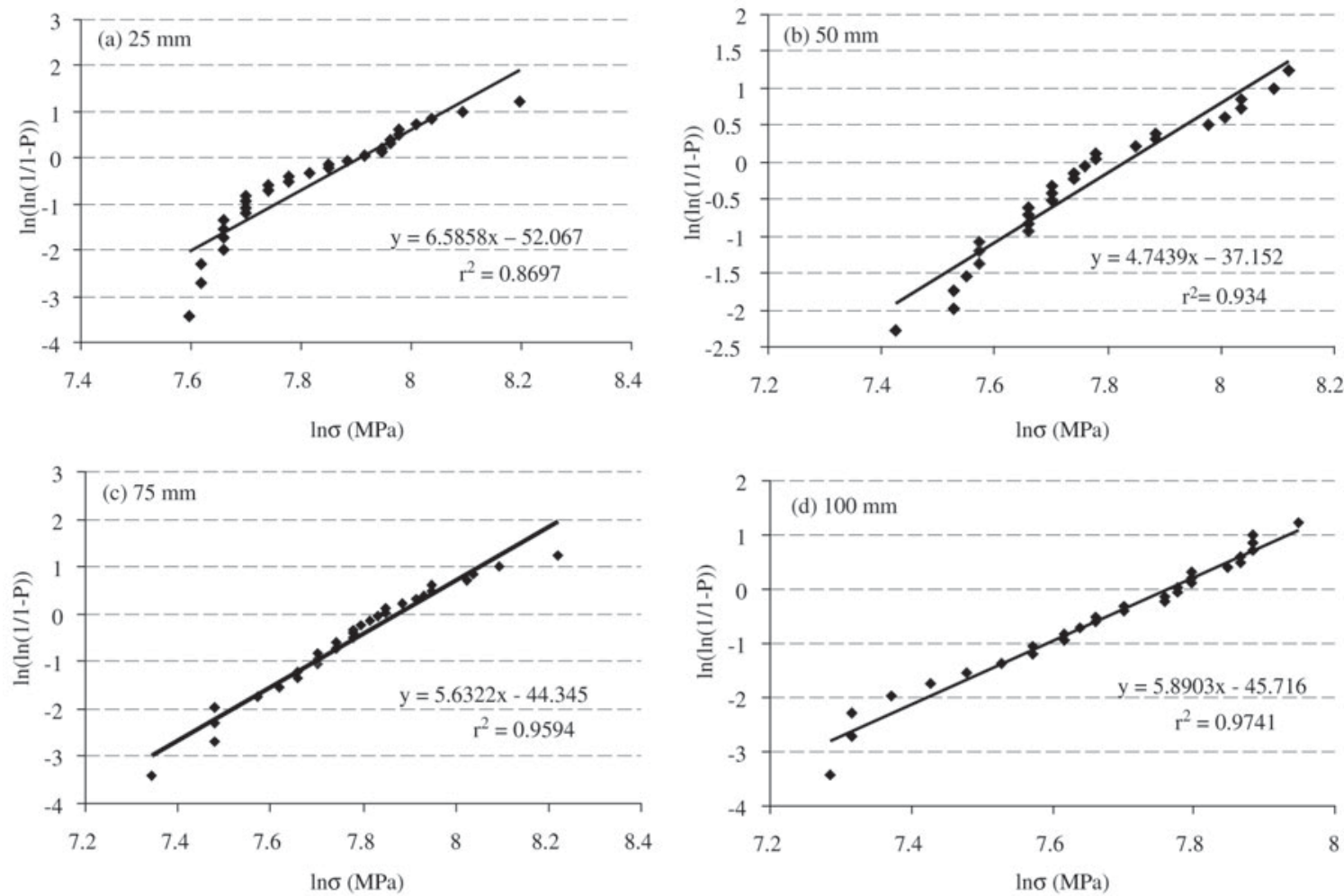

Figure 13. Weibull plots for tensile strength for glass fibres. Gage length $25 \mathrm{~mm}, 50 \mathrm{~mm}, 75 \mathrm{~mm}$ and $100 \mathrm{~mm}$. 


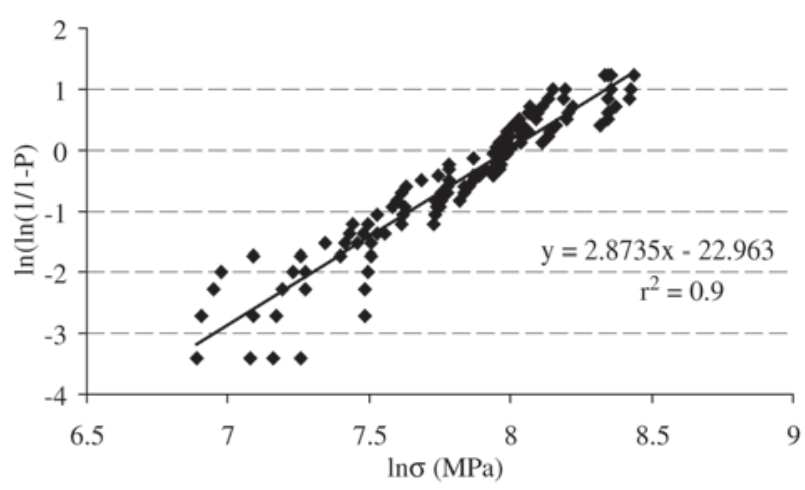

Figure 14. Weibull plots for tensile strength of carbon fibres for all test specimen length.

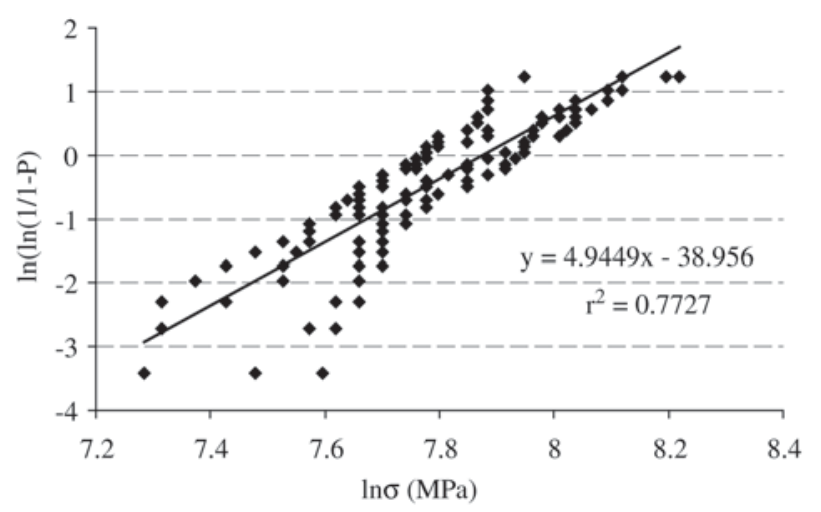

Figure 15. Weibull plots for tensile strength offor glass fibres for all test specimen length.

in structural composites, a high strenght carbon fibre and a glass fibre. In the range of specimen gage length tested, the tensile strength of glass fibres is within the range of 1.8-3.0 GPa (average 2.38 GPa) and tensile strength for carbon fibres is within the range of $1.8-3.8 \mathrm{GPa}$ (2.70 GPa).

Because such fibres have small diameter $(\sim 10 \mu \mathrm{m})$ it is not possible to use conventional strain-gages sensors in order to measure deformation and to calculate directly the Young's modulus. Thus, two methods were used to evaluate Young's modulus. The first followed a procedure described in ASTM D 3379 Standard, and the second followed a procedure which takes into account the interaction between testing equipment and specimen under test, named the rigidity method. By using the ASTM D 3379M standard, the calculated Young's modulus for carbon fibres is $\sim 183 \mathrm{GPa}$ and for glass fibres is $\sim 76 \mathrm{GPa}$. These values are lower than the Young's modulus calculated as- suming ideal Hookean behaviour for both fibres. The ASTM D 3379 method underestimates the carbon fibre Young's modulus in relation to literature values. On the other hand, by using the rigidy method a Young's modulus of $250 \mathrm{GPa}$ and $50 \mathrm{GPa}$ was found for carbon fibres and glass fibres, respectively. In relation to literature values the ASTM D3379M standard underestimates the carbon fibre Young's Modulus, and the rigidy method underestimates the glass fibre Young's Modulus. The differences in Young's modulus calculations from both methods can be explained by the fact that ASTM D3379M standard takes only the system rigidity (specimen/testing machine) into account, while the rigidity method distinguishes the system rigidity from the testing machine rigidity. As a consequence, testing machine rigidity can have a proportionally lower influence on testing stiffer ceramic fibres, e.g. carbon fibres, which reflects in the Young's modulus calculations.

Reinforcing fibres have defects generated during processing and from handling, such as ultramicropores, fibril misalignments and impurities, which are the main source for crack initiation and failure in fibres. These defects cause either lower and scattered strenght values. Weibull modulus for carbon fibre was in the range of 3.00 a 3.55 and for glass fibres in the range of 4.74 and 6.58 . So, the scatter in strength for carbon fibre is a bit higher than for glass fibres, although carbon fibre has more homogeneous quality than glass fibre have. In other words, carbon fibres have more flaws than glass fibres but they are evenly distributed throughout the length of the filament.

\section{Acknowledgments}

The authors express their thanks to FAPESP, Proc. 00/04359-3, and to Prof. Flaminio Levy Neto for useful discussions.

\section{References}

1. ASTM D 3379 - Tensile Strength and Young's Modulus for High-Modulus Single-Filament Materials

2. Guimarães, J.R.C.; Chawla, K.K., Metalurgia, v. 34, n. 249, p. 549-552, 1978.

3. Matthews, F.L.; Rawlings, R.D. Composite Materials: Engineering and Science, Chapman \& Hall, 1994.

4. Weibull, W. J. Appl. Mechanics, v. 18, p. 293-297, 1951.

5. Hitchon, J.W.; Phillips, D.C. Fibre Science and Technology, v. 12, p. 217- 233, 1979.

6. Belitskus, D. Fiber and Whisker Reinforced Ceramics for Structural Applications, Marcel Dekker, Inc. 1993.

7. Johnson, D.J. Carbon Fibres: Manufacture, Properties, Structure and Applications, Ch. 6, Induction to Carbon Science, Ed. Harry Marsh, Butterworths \& Co Ltd., 1989.

8. Hull, D.; Clyne, T.W. An Introduction to Composite 
Materials, Cambridge University Press, 2d․ 1996.

9. Pina, S.R.O.; Piorino-Neto, F.; Pardini, L.C., 23 $3^{\text {th }}$ Biennial Conference on Carbon, Newcastle-upon-Tyne-UK, 1997. 10. Lee, J.S.; Kang, T. J. Carbon, v. 35, n. 2, p. 209-216, 1997.
11. Tagawa, T.; Mujata,T. Materials Science and Engineering, v. A238, p. 336-342, 1997.

12. Zwaag, S. van der, Journal of Testing and Evaluation, v. 17, n. 5 , p. 292-298, 1989. 